\title{
Die Influenza-Pandemie der Saison 2009/2010
}

\author{
The 2009/2010 Pandemic
}

T. Schaberg ${ }^{1}$, R. Burger ${ }^{2}$

${ }^{1}$ Zentrum für Pneumologie - Diakoniekrankenhaus, Rotenburg/Wümme

2 Robert-Koch-Institut, Berlin

Im 20. Jahrhundert ist es durch das Auftreten von Shift-Varianten, d.h. Influenza-Virusstämmen mit einer weitgehenden Änderung ihrer antigenen Oberflächeneigenschaften, zu drei großen Pandemien gekommen. Die erste Pandemie wurde durch ein Influenza A-Virus H1N1 ausgelöst und hat zwischen 1918 und 1919 mehr als 30 Millionen Todesfälle weltweit gefordert [1]. Hierbei muss berücksichtigt werden, dass diese Pandemie in die Zeit unmittelbar nach dem 1. Weltkrieg fiel. $\mathrm{Zu}$ dieser Zeit herrschte in Europa und in vielen anderen Ländern eine schwierige wirtschaftliche Situation vor, in der Mangelernährung in großen Schichten der Bevölkerung die Regel war und nur sehr begrenzte medizinische Ressourcen zur Verfügung standen. Zweitens muss bei der Pandemie 1918/1919 berücksichtigt werden, dass insbesondere der großen Zahl von Patienten, die eine bakterielle Superinfektion erlitten, nicht geholfen werden konnte, da keine Antibiotika zur Verfügung standen. Drittens ist in jüngster Vergangenheit die Hypothese aufgestellt worden, dass die damalige therapeutische Strategie, an Influenza erkrankte Patienten mit hohen Dosen von Acetylsalicylsäure (8-30 g/Tag) zu behandeln, das Auftreten pulmonaler Hämorrhagien mit Todesfolge gefördert hat [2].

Die zweite Pandemie des 20. Jahrhunderts fand zwischen 1957 und 1963 statt und war durch ein Influenza-Virus A/H2N2 bedingt. Diese Pandemie hat ca. 1 Million Todesfälle weltweit gefordert. Die letzte große Pandemie des 20. Jahrhunderts wurde durch ein Influenza-Virus A/H3N2 in den Jahren 1968-1970 ausgelöst. Diese Pandemie hat wiederum ca. 1 Million Todesfälle weltweit bedingt.

Vereinfacht lassen sich die Charakteristika pandemischer Viren wie folgt beschreiben:

- Neuer Influenza-Stamm mit antigenem Shift

- Hohe Ansteckungsfähigkeit

- Auftreten der Epidemie in einer immunologisch naiven Population

- Fähigkeit der Influenza-Viren, in den peripheren Atemwegen und im Lungenparenchym zu binden und hier auch zu replizieren
- Vermehrtes Auftreten von Infektionen und schweren Verläufen bei Kindern, Jugendlichen und jungen Erwachsenen

- Auftreten außerhalb der klassischen Influenza-Saison

\section{Antigen-Shift: Das neue Influenza-Virus A(H1N1)v 2009 \\ $\nabla$}

Ein Antigen-Shift entsteht häufig durch die Reassortierung ganzer Gensegmente verschiedener Virus-Subtypen. Dieser biologische Vorgang ereignet sich bei der dualen Infektion eines Organismus (hier sind häufig Schweine die bevorzugte Spezies, da suszeptibel für Viren mit Ursprung im Menschen und im Vogel) mit 2 verschiedenen Arten von Influenza-Viren. Durch den Austausch der RNA-Segmente, die für die HA- oder NA-Proteine kodieren, entsteht ein neues Influenza-Virus, das im Vergleich zu den vorbestehenden Stämmen eine so stark veränderte antigene Oberflächenstruktur zeigt, dass weite Teile der Bevölkerung keine Grundimmunität besitzen oder als immunologisch naiv bezeichnet werden können.

Das neue Influenza-Virus A(H1N1)v 2009 hat als Vorläufer vermutlich das zuerst 1998 bei Schweinen beobachtete „USA Triple-Reassortment H1N1 Swine Influenza Virus“ gehabt, das aus dem Re-

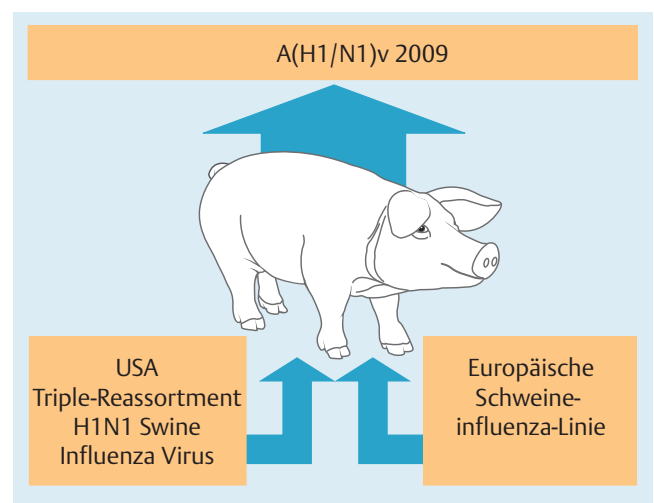

Abb. 1 Entwicklung des neuen Influenza-Virus A(H1N1)v 2009.
VNR

2760512010047430506

\section{Bibliografie}

Dol http://dx.doi.org/ 10.1055/s-0030-1255949 Pneumologie 2010; 64: 755-768

(c) Georg Thieme Verlag KG Stuttgart · New York ISSN 0934-8387

\section{Korrespondenzadresse} Prof. Dr. Tom Schaberg Zentrum für Pneumologie Diakoniekrankenhaus Rotenburg Elise-Averdiek-Str. 17 27356 Rotenburg Schaberg@diako-online.de 


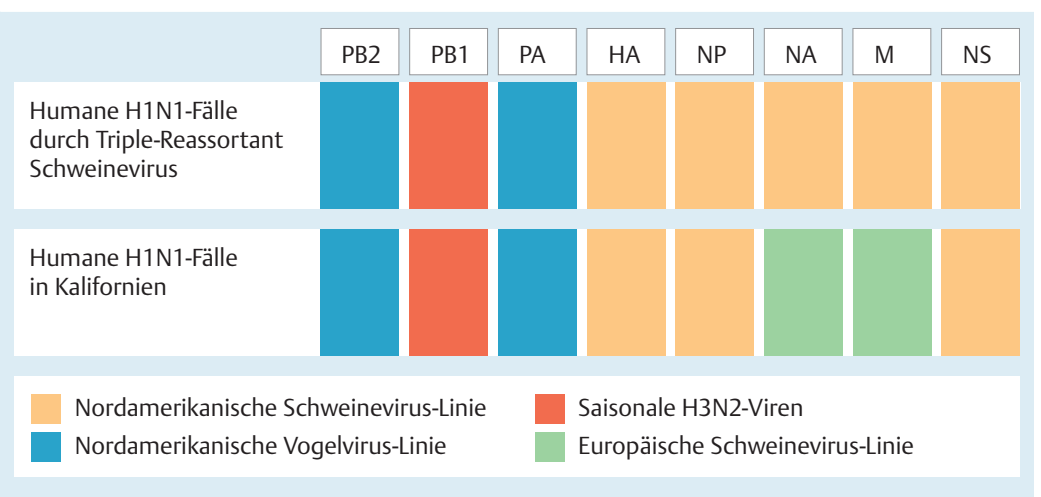

Abb. 2 Genotyp des neuen Influenza-Virus A(H1N1)v 2009 (nach Daten aus [3]).

Tab. 1 Epidemiologische Kennzahlen zu A(H1N1)v 2009 [27].

\begin{tabular}{|llll|} 
& Einheit & A(H1N1)v 2009 & Saisonale Influenza \\
\hline Ro (Basisreproduktionszahl) & & $1,1-1,8$ & $0,9-2,1$ \\
\hline Inkubationszeit & Tage & $1,5-3$ & $2-3$ \\
\hline $\begin{array}{l}\text { infektiöse Periode } \\
\begin{array}{l}\text { symptomatische Krankheits- } \\
\text { dauer }\end{array}\end{array}$ & Tage & $?$ & $2-4$ \\
\hline \begin{tabular}{l} 
Virusausscheidung \\
\hline
\end{tabular} & Tage & $3-5$ & $2-4$ \\
\hline
\end{tabular}

assortment einer in den USA endemischen Schweine-Influenza-Viruslinie und einer humanen Influenza A/H3N2-Linie entstanden ist [3]. Vermutlich im Jahre 2008/2009 ist es in den USA zu einem weiteren Reassortment zwischen dem „USA Triple-Reassortment H1N11 Swine Influenza Virus" und einer in der EU endemischen Schweine-Influenza-Linie gekommen. Hieraus ist das neue Influenza-Virus A(H1N1)v 2009 entstanden [3].

Das neue Influenza-Virus hat aus der europäischen Schweine-Influenza-Linie die Genom-Abschnitte NA und M übernommen [4,5].

\section{Hohe Ansteckungsfähigkeit \\ $\nabla$}

Die Ansteckungsfähigkeit von Influenza-Viren lässt sich durch zwei wesentliche Parameter beschreiben. Es ist dies zum einen die Reproduktionszahl (Ro), die die Anzahl neuer Fälle pro erkranktem Individuum beschreibt. Während die Reproduktionszahl bei der saisonalen Influenza bei 1-2 liegt, haben frühere Pandemien Reproduktionszahlen von 3 und mehr erreicht. Für die Neue Influenza A(H1N1)v 2009 ist die Reproduktionszahl zunächst zu hoch eingeschätzt worden, tatsächlich lag der Wert bei retrospektiver Betrachtung bei 1,1-1,7 [6-9]. Bei Ausbrüchen in Schulen sind jedoch auch extrem hohe Ro-Werte bis 3,0-3,6 beobachtet worden [6].

Der zweite Parameter zum Beschreiben der Ansteckungsfähigkeit ist die Transmissionsrate, d.h. die Wahrscheinlichkeit, sich beim Kontakt mit einem an Influenza erkrankten Patienten zu infizieren. Die Transmissionsrate wird für die saisonale Influenza zwischen 10 und 15\% beschrieben und lag bei der Neuen Influenza vermutlich zwischen 4 und $28 \%[6,7,10]$.

\section{Immunologische Naivität weiter Teile der Weltbevölkerung}

Die Arbeitsgruppe um K. Hancock fand bei $4 \%$ der untersuchten Probanden, die nach 1980 geboren waren, präexistierende kreuzreagierende Antikörper (Hämagglutination-Inhibitions-Titer) gegenüber $A(H 1 N 1) v 2009$ mit einem Titer von $\geq 40$ [11]. Bei Personen, die vor 1950 geboren waren, fanden sich dagegen bei $34 \%$ Titer von 80 oder mehr gegen das neue Virus [11]. Somit war relativ rasch klar, dass das neue Influenza-Virus tatsächlich weltweit bei Personen unterhalb des 60. Lebensjahres auf eine immunologisch naive Bevölkerungsgruppe traf.

Ebenso klar war, dass die Impfung mit vorhergehenden saisonalen, nicht adjuvantierten oder adjuvantierten Influenza-Impfstoffen keine oder nur eine sehr geringe Kreuzreaktivität hinsichtlich der Antikörperantwort gegenüber A(H1N1)v 2009 in allen Altersgruppen verursachte [11].

Eine weitere Erklärung für die offenbar bei Älteren bestehende Immunität ergibt sich aus der Tatsache, dass sich im Blut von Spendern, das vor der Pandemie 1957 eingefroren worden ist, sowohl CD8- als auch CD4-T-Lymphozyten mit einem Memory-Phänotyp haben finden lassen [12]. Memory-T-Zellen können zwar nicht die Infektion verhindern, wenn keine konservierten B-Zell-Epitope vorhanden sind, die für eine Antikörperproduktion sorgen können, sie sind aber in der Lage, infizierte Zellen über die Aktivierung von T-Killerzellen zu zerstören und damit unter Umständen leichtere Verläufe zu induzieren [12].

\section{Bindungs- und Replikationsorte von nAH1/N1-Viren}

Entscheidend für die Pathogenität von InfluenzaViren ist die Fähigkeit, nicht nur im Bereich der Mukosa des oberen Respirationstraktes oder der Trachea zu binden, sondern auch tiefe Abschnitte der Atemwege zu erreichen. Entscheidend hierbei ist zum einen die Tatsache, dass in den tiefen Atemwegen höhere Temperaturen vorherrschen. Saisonale Influenza-Viren haben ihr Replikations-Temperatur-Optimum bei niedrigeren Temperaturen, wie sie in den oberen und mittleren Atemwegen herrschen. Zum anderen binden saisonale Influenzaviren nur an dem $\alpha 2,3-Z e l l-R e-$ zeptor auf der Mukosa der oberen Atemwege, wohingegen das neue Influenza-Virus auch an dem $\alpha 2,6$-Zell-Rezeptor der Mukosa der tiefen Atemwege und der alveolären Pneumozyten binden kann [13]. Bereits relativ früh konnte im Tiermodell des Frettchens nachgewiesen werden, dass ein Virusbefall des Frettchen-Lungengewebes mit 


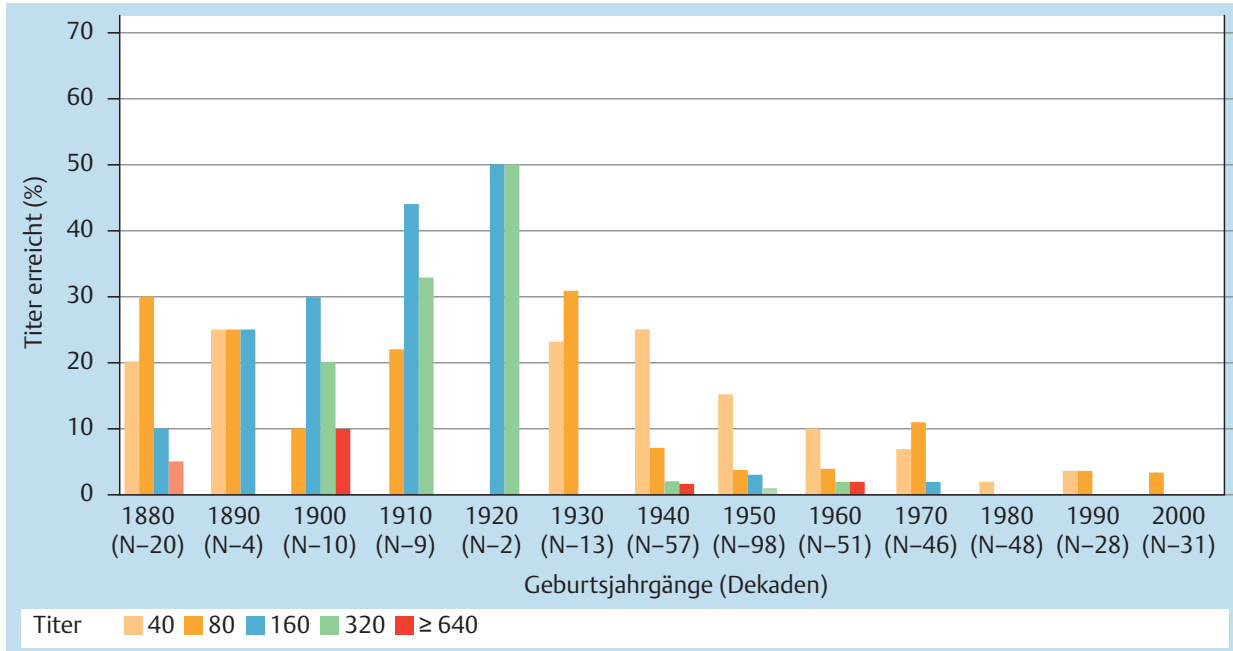

Abb. 3 Präexistierende kreuzreagierende Antikörper (Hämagglutination-InhibitionsTiter) gegenüber $\mathrm{A}(\mathrm{H} 1 \mathrm{~N} 1) \mathrm{v}$ 2009 in verschiedenen Altersgruppen (nach Daten aus [11]).

der saisonalen Virusvariante H1N1 nur bei 10 $30 \%$ der Tiere beobachtet werden konnte, wohingegen das neue Influenza A-Virus H1N1 einen Virusbefall der tiefen Atemwege bei 40-70\% der infizierten Tiere zeigte [14]. Ebenfalls frühzeitig konnte gezeigt werden, dass im Frettchen die Virusreplikation des neuen Influenza-Virus sich gleichmäßig im Bereich der Mukosa der Trachea, der Bronchien und der Bronchiolen abspielt [15]. Eine viral bedingte Pneumonitis ist dann auch in den obduzierten Fällen frühzeitig gezeigt worden $[16,17]$. Die Fähigkeit von Influenza-Viren, peripher in den Atemwegen zu binden und zu replizieren, ist besonders gefährlich, da es sich bei dem Influenza-Virus um eine lytische Infektion handelt, bei der im Rahmen der Replikation die Wirtzelle schwer geschädigt oder abgetötet wird. Es erscheint daher die Tiermodell-Ergebnisse zu bestätigen, dass brasilianische Pathologen bei 20 verstorbenen Patienten einen diffusen Alveolarschaden (DAD) nachweisen konnten, 6 dieser Patienten eine nekrotisierende Bronchiolitis aufwiesen und weitere 5 dieser Patienten eine ausgeprägte periphere pulmonale Hämorrhagie zeigten [17].

Verantwortlich für schwere und vor allem tödliche Verläufe ist nach einer Infektion mit A(H1N1) v 2009 neben der viral induzierten und/oder bakteriell superinfizierten Pneumonie vor allem aber eine massive und überschießende inflammatorische Reaktion mit massiven Plasmaspiegel-Erhöhungen einer Vielzahl von proinflammatorischen Zytokinen (IL-1, IL-6, IL-8, IL-10,IL-12p70, IL-15, TNF- $\alpha$ und $\gamma$-Infererone) gewesen, die auch als „cytokine storm“ bezeichnet worden ist [13].

\section{Altersbezogene Risikogruppen \\ $\nabla$}

Ein historisches Charakteristikum pandemischer Viren ist die besondere Anfälligkeit von Kindern, Jugendlichen und jungen Erwachsenen für die Infektion. Dieses Kriterium hat die Neue Influenza ebenfalls gezeigt. Zum Höhepunkt der Epidemie
Tab. 2 Virusbefall und Virusreplikation durch A(H1N1)v 2009 in den tiefen Atemwegen im Tiermodell.

\begin{tabular}{|lll|}
\hline Tiermodell Frettchen & $\begin{array}{l}\text { Virusbefall des } \\
\text { Lungengewebes [30] }\end{array}$ & $\begin{array}{l}\text { Virusreplikations- } \\
\text { Orte [45] }\end{array}$ \\
\hline saisonales H1N1-Virus & $10-30 \%$ & $\begin{array}{l}\text { nasal }>\text { periphere } \\
\text { Atemwege }\end{array}$ \\
\hline A (H1N1) v 2009 & $40-70 \%$ & $\begin{array}{l}\text { Trachea = Bronchien }= \\
\text { Bronchiolen }\end{array}$ \\
\hline
\end{tabular}

in Deutschland lag die Positivrate, d.h. der Anteil des $A(H 1 N 1) v$ 2009-Nachweises in Relation zur Anzahl der untersuchten Proben, bei den 0- bis 1-Jährigen bei $27 \%$, den 2- bis 4-Jährigen bei 34 $\%$, den 5- bis 14 -Jährigen bei $62 \%$, den 15 - bis 34 Jährigen bei $44 \%$, den 34 - bis 59 -Jährigen bei $30 \%$ und bei Personen, die 60 Jahre oder älter waren, nur bei $13 \%$ [18].

Die besondere Bevorzugung jüngerer Menschen, nicht nur hinsichtlich der Häufigkeit der Erkrankung, sondern auch hinsichtlich der Schwere, wurde bereits relativ früh durch die Publikation erster klinischer Daten deutlich. So konnte in Mexiko bereits frühzeitig für das Jahr 2009 eine deutlich erhöhte Pneumonie-Sterblichkeit in der Population der 5- bis 50-Jährigen gezeigt werden (7,6-10,7-fach höher als 2008/09) [16].

Auch die weitere Publikation klinischer Daten [19] zeigte klar, dass Personen unterhalb des 65. Lebensjahres deutlich schwerer erkrankten als die über 65-Jährigen, die zu diesem Zeitpunkt nur 5\% der hospitalisierten Patienten in den USA ausmachten [19].

Die Häufigkeit schwerer Verläufe bei jüngeren Menschen darf jedoch nicht mit der sogenannten Case-Fatality-Rate verwechselt werden. Diese war zum Beispiel in Kalifornien für Kinder bis zum 17. Lebensjahr mit 0,01-0,05 deutlich niedriger als diejenige für Personen zwischen 18 und mehr als 70 Lebensjahren, wo sie um 0,1 betrug. Dies heißt, dass ältere Menschen zwar weniger oft schwer erkrankten, dass aber ältere Menschen, wenn sie erkranken, besonders häufig schwere und tödliche Verläufe gezeigt haben [20].

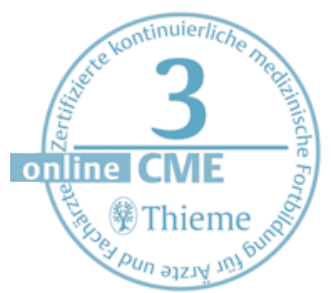




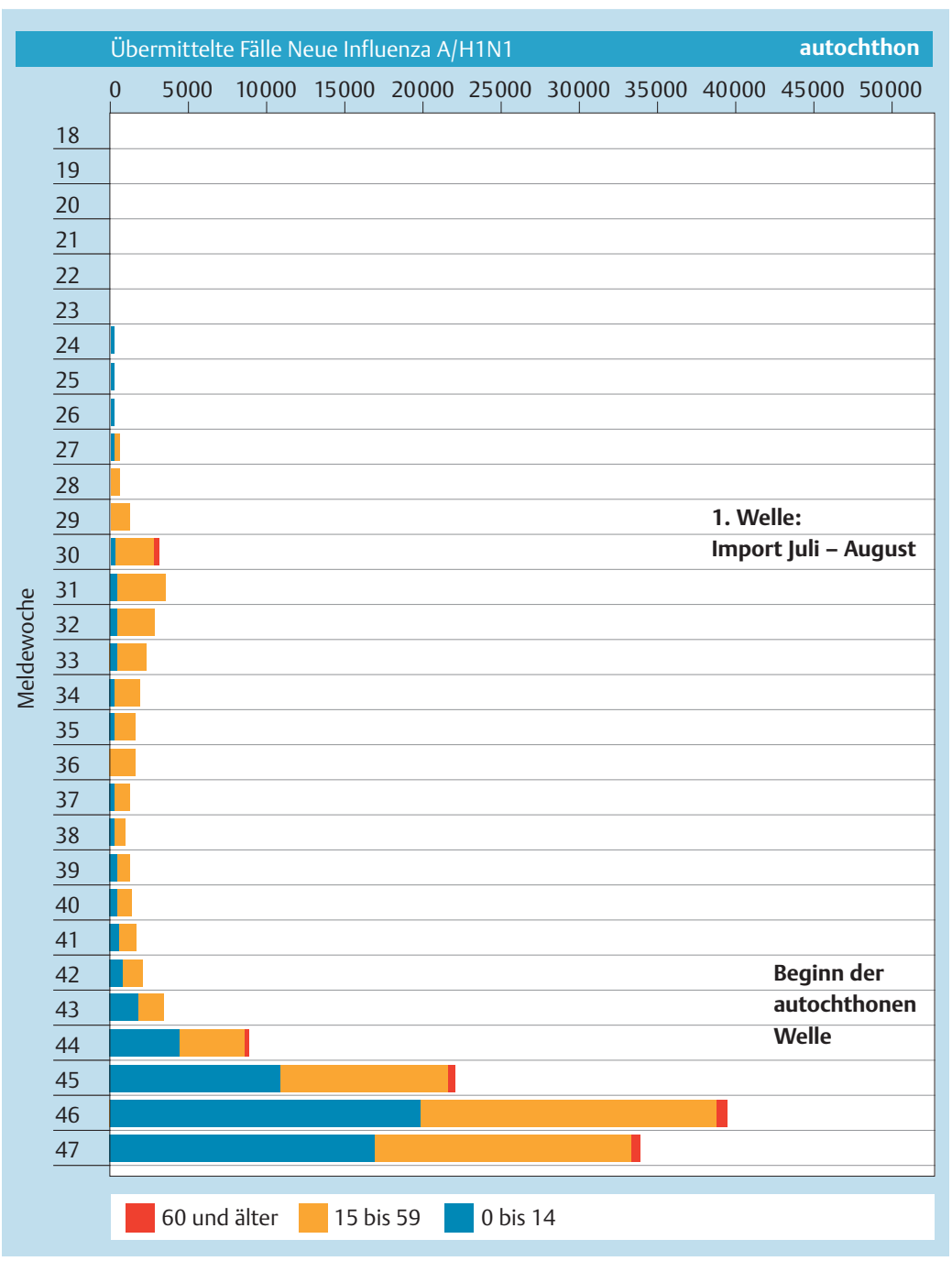

Abb. 4 Die Sommerwelle (Daten RKI 2009).
Nach den ersten aus Mexiko berichteten 900 Fällen, von denen 60 tödlich verliefen, musste man von einer Case-Fatality-Rate von 6\% ausgehen. Diese lag dramatisch oberhalb der Case-FatalityRate einer saisonalen Influenza, die normalerweise bei $\leq 0,1 \%$ veranschlagt wird. Im Verlauf der Epidemie ist dann die Case-Fatality-Rate jedoch deutlich niedriger beobachtet worden (weltweit 0,5\%, Mexiko 1,0\%, USA 0,05\%, Großbritannien $0,026 \%$, EU ohne Großbritannien 0,012\%) $[13,21,22]$.

\section{Saisonales Auftreten \\ $\nabla$}

Aus der Influenza-Epidemie 1918/1919 sind Daten über den Anstieg von Todesfällen berichtet. Trägt man die Todesfälle zwischen dem Juni 1918 und dem Mai 1919 auf, so zeigt sich ein erster kleiner Peak im Sommer zwischen Juni und August, gefolgt von einem zweiten Peak, beginnend im Oktober mit seinem Maximum im November und einem Folgepeak dann noch einmal im März des folgenden Jahres [1]. Auch andere vorausgegangene pandemische Influenza-Epidemien zeigen häufig einen zunächst im Sommer auftretenden kleinen Peak der Erkrankungshäufigkeiten [22]. Zwischen der 28. und 36. Woche des Jahres 2009 konnte ein solcher Anstieg von Influenza-Erkrankungen, verursacht durch das neue Influenza $A(H 1 N 1) v$ 2009-Virus, auch in Deutschland beobachtet werden [18]. Es handelte sich hierbei jedoch um importierte Fälle.

Eine ähnliche Häufung der Infektion im Sommer ist auch aus den Vereinigten Staaten von Amerika berichtet worden [23].

\section{Die Pandemie 2009/2010}

$\nabla$

Somit waren im Frühsommer des Jahres 2009 die wesentlichen Voraussetzungen für eine pandemische Ausbreitung des neuen Influenza-Virus gegeben:

- Antigen-Shift

- Übertragung von Mensch zu Mensch mit hoher Transmissionsrate

- Eine weitgehende immunologische Naivität großer, vor allem jüngerer Bevölkerungsgruppen.

Nach den Erfahrungen mit dem SARS-Virus und dem Auftreten hoch pathogener aviärer Influenzastämme (Influenza A/H5N1) wurden in den darauf folgenden Jahren weltweit Vorbereitungspläne für eine neue Influenza-Pandemie entwickelt [24]. Nach den Definitionen, die in diesem Rahmen von der WHO beschlossen wurden, galt das Auftreten einer Pandemie dann für gegeben, wenn eine Influenza-Shift-Variante zu Ausbrüchen von Influenza in 2 oder mehr Ländern einer WHO-Region führt (Pandemiestufe 5). Die Pandemiestufe 6 enthielt die Definition, dass eine Influenza-Shift-Variante zusätzlich zu einer epidemischen Situation in einer zweiten WHO-Region führt. Diese Situation war bereits frühzeitig im Frühsommer 2009 gegeben [25]. Man muss allerdings kritisch anmerken, dass die 2009 geltenden Definitionen lediglich die Ausbreitung eines neuen Virus weltweit als Definitionsgrundlage benutzt haben und die Schwere des Krankheitsverlaufes nicht mitberücksichtigt wurde. Hierzu ist allerdings anzumerken, dass es selbstverständlich eher möglich ist, die endemische Ausbreitung eines neuen Virustyps zu beobachten als die Schwere der Erkrankung, die durch dieses Virus induziert wird, frühzeitig zu beschreiben.

\section{Epidemiologie der A(H1N1)v 2009-}

Pandemie 2009/2010

Am 29. April 2009 ist das endemische Auftreten des neuen Influenza-Virus aus 9 Ländern, die WHO-Mitglied sind, berichtet worden, am 11 . Juni 2009 bereits aus 74 Ländern und am 1. Juli 2009 aus 120 Ländern [25].

Während es sich bei dem frühen Auftreten von Influenza-Infektionen in Europa und den USA zunächst um importierte Infektionen, vermutlich aus Lateinamerika (Mexiko) gehandelt hat, trat 
Tab. 3 Die Neue Influenza in den USA - Schätzung des CDC im Dezember 2009 ( www.cdc.gov/flu/weekly).

\begin{tabular}{lc} 
A (H1N1)v 2009 & Mid-Level-Range \\
\hline Fälle & \\
0 - 17 Jahre & 16 Millionen \\
18 - 64 Jahre & 27 Millionen \\
$\geq 65$ Jahre & 4 Millionen \\
alle Fälle & 47 Millionen \\
\hline Hospitalisierungen & \\
0 - 17 Jahre & 71000 \\
18 -64 Jahre & 121000 \\
$\geq 65$ Jahre & 21000 \\
alle Hospitalisierungen & 213000 \\
\hline Todesfälle & \\
0 - 17 Jahre & 1090 \\
18 - 64 Jahre & 7450 \\
$\geq 65$ Jahre & 1280 \\
alle Todesfälle & 9820
\end{tabular}

eine zweite Infektionswelle mit autochtonen, d.h. von Mensch zu Mensch übertragenen Infektionen, im Spätsommer 2009 in den USA und im Herbst 2009 in Europa auf [18,23,25,26].

\section{USA}

Im April 2010 hat das CDC geschätzt, dass in den USA zwischen April und November 200959 Millionen Personen an einer H1N1-Infektion erkrankt sind. 90\% der Erkrankungen betrafen die Alterskohorten 0-64 Jahren und weniger als 10\% die Alterskohorte 65 Jahre oder älter [23]. Im gleichen Zeitraum sind in den USA ca. 265000 Personen wegen einer H1N1-Infektion hospitalisiert worden, wobei sich die gleiche Altersverteilung zeigte wie bei den Erkrankungen. Nach diesen Schätzungen sind in den USA 12000 Personen an einer H1N1-Infektion verstorben, von denen zirka $12 \%$ älter als 64 Jahre waren. Der Gipfel der Erkrankungen lag in den USA zwischen der 40. und 50. Kalenderwoche [23].

Noch bemerkenswerter sind Seroprevalenz-Untersuchungen, die z. B. in Pittsburgh zeigen konnten, das $21 \%$ der Gesamtbevölkerung und $45 \%$ der 10- bis 19-Jährigen sich infiziert haben [27].

\section{Deutschland}

Nach der ersten schwachen Sommerwelle durch importierte Infektionen über Urlaubsrückkehrer breitete sich das neue Influenza-Virus auch in Deutschland zwischen der 42. und 47. Woche sehr rasch aus, um dann bereits in der 50 . Woche des Jahres 2009 einen Rückgang zu zeigen.

Legt man den Praxisindex, d.h. die Zahl der ärztlichen Konsultationen wegen akuter respiratorischer Erkrankungen, die durch den SentinentalVerbund der Arbeitsgemeinschaft Influenza erhoben werden, zu Grunde, zeigt sich ebenfalls ein Gipfel um die 47. Woche. Besonders betroffen waren Kinder im Alter von 0-4 Jahren und von 514 Jahren. Der Gipfel des Praxisindex für die Altersgruppe der 15-59 Jahre alten Personen war deutlich geringer ausgeprägt [18].

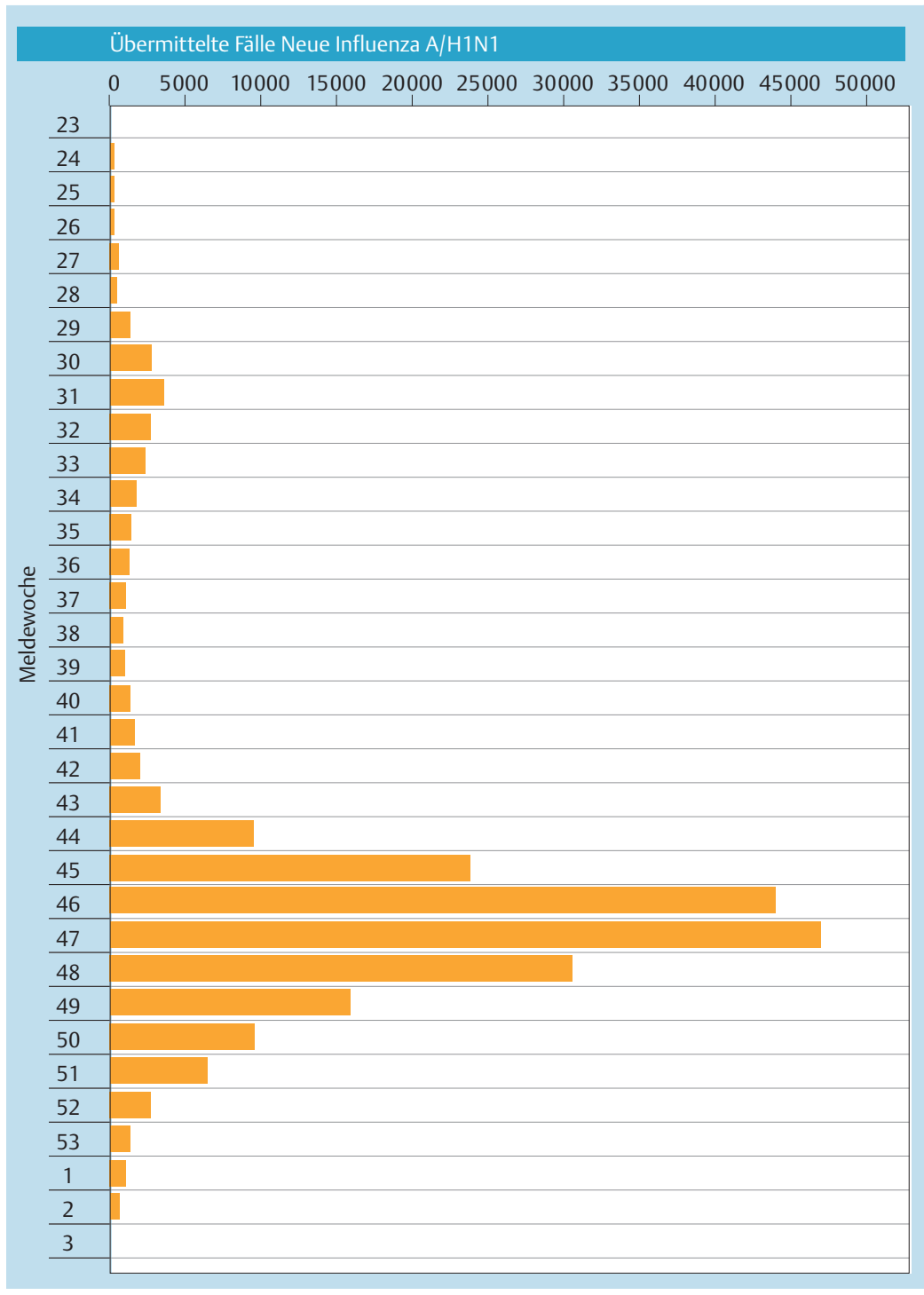

Insgesamt wurden dem Robert Koch-Institut bis zur 13. Kalenderwoche des Jahres 2010226.137 Fälle von pandemischer Influenza übermittelt. Die Melderaten zeigen einen kleinen Sommergipfel zwischen der 29. und 35. Woche, gefolgt von einem Wiederanstieg zu einer massiven Welle zwischen der 43. und 52. Woche. In Spitzenzeiten zwischen der 46. und 47. Woche wurden wöchentlich mehr als 40000 Neuerkrankungen gemeldet. Interessant ist auch ein Blick auf die Gesamt-Inzidenzraten ab der 18. Kalenderwoche des Jahres 2009 bis zum März 2010. Danach betrug die Gesamtinzidenz in der Altersgruppe 0-1 234 pro 100000 , in der Altersgruppe $2-4$ Jahre 377 pro 100000 , in der Altersgruppe 5-14 Jahre 839 pro 100000 , in der Altersgruppe 15 - 34 Jahre 310 pro 100000 , in der Altersgruppe der 35- bis 59-Jährigen 100 pro 100000 und in der Altersgruppe der 60-Jährigen und älteren lediglich 12 pro 100000 . Die Gesamtinzidenz der Bevölkerung errechnet sich somit bei 205 pro 100000 [18]. Die höchste Positivrate des Virusnachweis fand sich zwischen der 48. und 51. Kalenderwoche. Dies entspricht auch dem Verlauf der Todesfälle in
Abb. 5 Meldedaten der Neuen Influenza beim RKI 2009/2010.

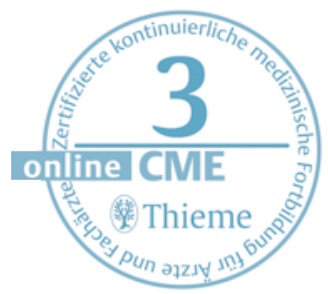




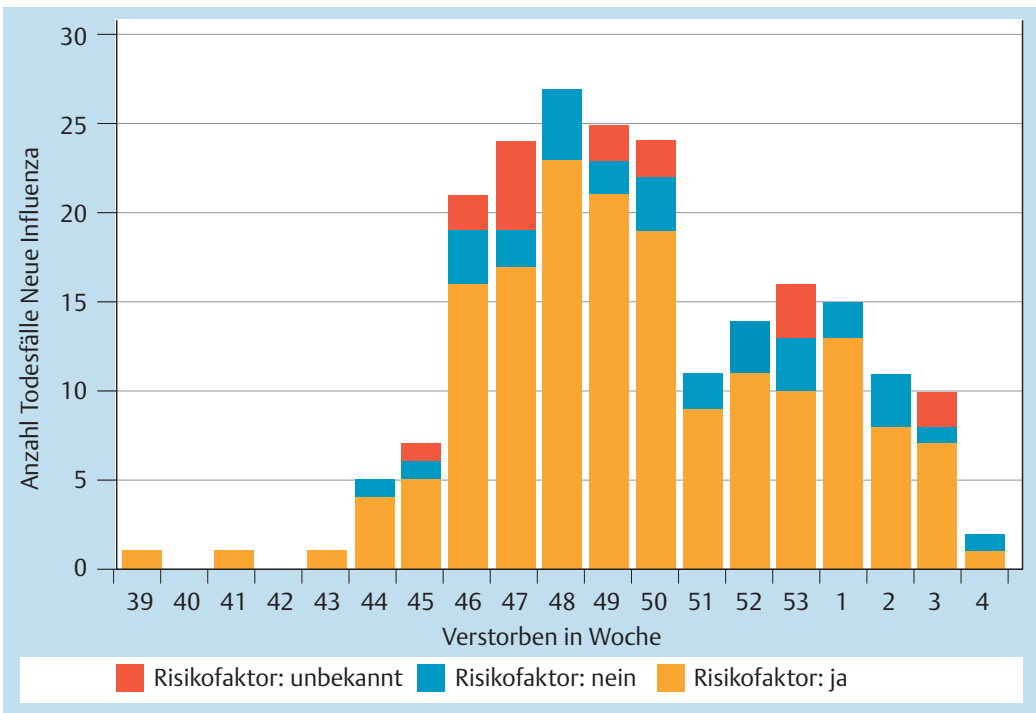

Abb. 6 Todesfälle durch die Neue Influenza in Deutschland 2009/2010.
Deutschland. Bis zur 13. Kalenderwoche 2010 wurden 253 Todesfälle gemeldet, von denen 86\% einen Risikofaktor (Grundkrankheit oder Schwangerschaft) aufgewiesen haben .

Das Maximum der Verstorbenen findet sich zwischen der 46. und 50. Woche mit einem zweiten kleineren Gipfel zwischen der 51. Woche 2009 und der 3. Woche 2010. Die Inzidenz der Todesfälle zeigte für Deutschland ein Maximum für die 0 - bis 1 -Jährigen mit 0,44 pro 100000 , gefolgt von 0,31 pro 100000 in der Gruppe der 35- bis 59Jährigen. Für die übrigen Altersgruppen lag die Inzidenz der Todesfälle bei ca. 0,2 pro 100000 [18]. Nach bisher vorliegenden Daten verstarb der größte Teil dieser Patienten nach der Hospitalisierung innerhalb von 14 Tagen.
Die weltweite Ausbreitung der Neuen Influenza ist durch die WHO gut dokumentiert [25]. Während im August 2009 eine hohe Influenza-Aktivität lediglich aus Amerika, Südamerika und Australien gemeldet wurde, fand sich im November 2009 nahezu weltweit eine hohe oder regional deutlich erhöhte Influenza-Aktivität, auch in Europa und Asien.

Hierbei muss allerdings bedacht werden, dass Daten aus Afrika und der Volksrepublik China nur in sehr geringem Umfang zur Verfügung standen. Im Dezember 2009 war die stark erhöhte InfluenzaAktivität in Europa bereits weitgehend rückläufig, blieb jedoch in Nordamerika und Kanada sowie Teilen Südamerikas auf einem hohen Niveau [25].

\section{Entwicklung des Influenzavirus A(H1N1)v 2009 in der Saison 2009/10}

In der Saison 2009/2010 sind im Nationalen Referenzzentrum für Influenza im Robert KochInstitut in Berlin insgesamt 2.190 pandemische $\mathrm{A}$ (H1N1)v 2009-Viren hinsichtlich ihrer Antigenund/oder genetischen Eigenschaften untersucht worden [18]. Die seit Oktober 2009 isolierten $1.730 \mathrm{~A}(\mathrm{H} 1 \mathrm{~N} 1) \mathrm{v}$ 2009-Viren reagieren sehr gut mit dem Immunserum gegen den im pandemischen Impfstoff enthaltenen Stamm A/California/ 7/2009, womit eine enge Verwandtschaft mit dem Impfstamm belegt ist [18]. Die molekulare Analyse des Hämagglutinin-Gens hat gezeigt, dass sich die Viren weltweit zwei großen Gruppen zuordnen lassen, die wiederum in verschiedene Subgruppen unterteilt werden können. Eine dieser zwei weltweit zirkulierenden Gruppen ist durch eine Aminosäuren-Substitution im Bereich

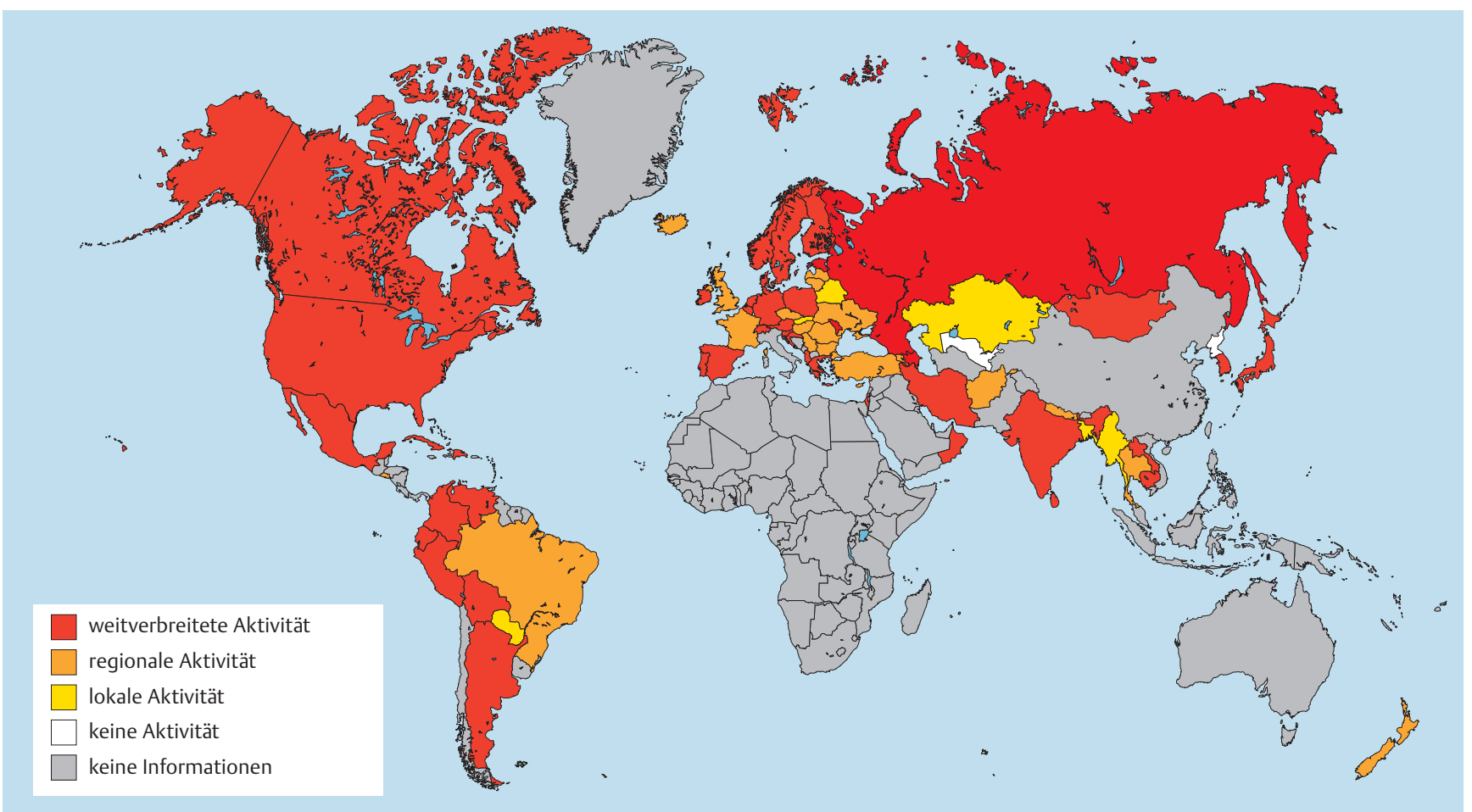

Abb.7 Weltweite Epidemiologie der Neuen Influenza im November 2009 (Quelle: www.who.int/crs/2010_04_01/en/index.html). 
S203 T gekennzeichnet. Seit Oktober 2009 wurden in Deutschland ausschließlich $A(H 1 N 1) v$ 2009-Viren mit dieser Substitution isoliert [18].

G. Neumann konnte zeigen, dass das neue Influenza-Virus molekularbiologisch gesehen eine deutlich höhere Verwandtschaft zu niedrig pathogenen Influenza-Viren aufweist als zu hoch pathogenen Influenza-Viren [28].

Insgesamt 1.546 pandemische Influenza-Viren sind im Nationalen Referenzzentrum hinsichtlich ihrer Sensitivität gegenüber den NeuraminidaseInhibitoren Zanamivir und Oseltamivir entweder genotypisch und/oder phänotypisch untersucht worden [18]. Bei 99,5\% der Viren waren keine bekannten Resistenzmutationen nachweisbar. Ein sensitiver Phänotyp konnte bei allen untersuchten Virusisolaten nachgewiesen werden. Lediglich bei acht $A(H 1 N 1) v$ 2009-Viren wurde eine Resistenz gegenüber Oseltamivir nachgewiesen, alle Viren waren jedoch gegenüber Zanamivir sensibel. Hingegen waren alle 984 analysierten Viren des neuen Influenza-Stammes gegenüber Amantadin resistent [18].

Weltweit sind bis zum 1. April 2010 insgesamt 268 Oseltamivir-resistente pandemische Influenza-Viren erfasst worden [25,29]. Zur weiteren Übertragung von Mensch zu Mensch ist es jedoch nur in Einzelfällen gekommen [30]. Alle weltweit bisher nachgewiesenen Oseltamivir-resistenten Viren zeigten sich sensitiv gegenüber Zanamivir [31].

\section{Saisonale Influenza-Viren in der Saison 2009/2010}

In der Saison 2009/2010 hat das neue InfluenzaVirus die saisonalen Viren nahezu komplett verdrängt. Mit Ausnahme von China (Influenza B) lag die Rate saisonal nachgewiesener InfluenzaViren bei $1-5 \%$ [25].

\section{Diagnostik}

Wie bei der saisonalen Influenza kann in der laufenden Epidemie bei einer typischen klinischen Präsentation insbesondere zu Zeiten mit einer hohen Nachweisrate von Viren in der laufenden Surveillance die Diagnose einer A(H1N1)v 2009Infektion klinisch gestellt werden [32].

Bereits sehr frühzeitig wurde deutlich, dass die kommerziell verfügbaren „Influenza-Schnellteste“, die auf einem Influenza A-Antigen-Nachweis beruhen, nicht ausreichend sensitiv (11-70\%) waren [13]. Zum Goldstandard des Virusnachweises wurde daher die konventionelle oder „real-time“ Reverse-Transkriptase-PolymeraseKettenreaktion (RT-PCR) und zwar sowohl für das durch einen Nasen-Rachenabstrich gewonnene Material als auch für Sekrete aus dem tiefen Respirationstrakt [33]. Die Überlegenheit der RTPCR besteht auch gegenüber der direkten oder indirekten Immunofluoreszenz-Technik. Viruskulturen dienen überwiegend der Surveillance und sind nur unter sehr ausgewählten Fragestellungen
Tab. 4 Genetik und Pathogenität von Influenza-Viren [28].

\begin{tabular}{|lllll|}
\hline Protein & Position & $\begin{array}{l}\text { Pathogenität } \\
\text { niedrig }\end{array}$ & $\begin{array}{l}\text { Pathogenität } \\
\text { hoch }\end{array}$ & A (H1N1) v2009 \\
\hline PB2 & 627 & Glu & Lys & Glu \\
\hline PB2 & 701 & Asp & Asn & Asp \\
\hline PB1-F2 & 66 & Asn & Ser & Truncated (11aa) \\
\hline HA & Cleavage site & Single basic AA & Multiple basic AA & Single basis AA \\
\hline NS1 & 92 & Asp & Glu & Asp \\
\hline & C-Terminus & $\begin{array}{l}\text { Arg-Ser-Glu-Val } \\
\text { Deletion }\end{array}$ & Glu-Ser-Glu-Val & $\begin{array}{l}\text { 11 C-terminal AA } \\
\text { truncated }\end{array}$ \\
\hline
\end{tabular}

z.B. bei massiv immunsupprimierten Patienten (HIV-Infektion, Z.n. Transplantation) hilfreich [13].

\section{Klinik der Neuen Influenza}

Die Inkubationszeit nach der Infektion wird für A (H1N1)v 2009 mit 1,5-3 Tagen angenommen, in Einzelfällen mit bis zu 7 Tagen $[6,7,34]$. Die Dauer der Virusausscheidung betrug bei unkompliziertem Krankheitsverlauf bis zu 8 Tage [35,36], bei kompliziertem Krankheitsverlauf bis zu 3 Wochen [37]. Bei der Masse der Erkrankten war der Verlauf ausgesprochen kurz und milde und ging mit leichten Halsschmerzen, Muskelschmerzen, leichtem Fieber und Rhinitis über 3-5 Tage einher $[19,38]$. Auch scheint der Anteil asymptomatischer Infektionen insgesamt groß gewesen zu sein, obwohl hierüber noch kaum Daten vorliegen [13]. Reinfektionen können offenbar vorkommen, ihre genaue Anzahl ist jedoch noch nicht bekannt [39].

Die klinische Präsentation der Influenza-Erkrankung bei der Neuen Influenza hat sich bei schwereren Erkrankungsverläufen in vielfältiger Weise von dem Krankheitsbild der saisonalen Influenza unterschieden [40].

Hervorstechendes Merkmal war zunächst die ungleich größere Betroffenheit von Kindern, Jugendlichen und jungen Erwachsenen im Vergleich zu Patienten, die älter als 65 Jahre waren.

Eine Besonderheit aus klinischer Sicht ergibt sich für die Neue Influenza durch den relativ hohen Anteil von Personen, der neben Atemwegsbeschwerden an Erbrechen und Übelkeit bzw. Durchfällen gelitten hat. Nach den publizierten klinischen Daten litten von den hospitalisierten Influenzapatienten 35\% an Übelkeit und Erbrechen und $20 \%$ an Durchfällen $[19,20,41]$.

Ebenfalls auffällig war die hohe Rate von pulmonalen Infiltraten, die bei hospitalisierten Patienten mit einer neuen Influenza-Infektion gesehen worden sind $[10,16,20,42-45]$. In der Publikation von S. Jain lag die Rate von Infiltraten bei Patienten, die nicht auf eine Intensivstation aufgenommen worden sind und die Krankheit überlebt haben, bei $28 \%$, wohingegen die Rate von pneumonischen Infiltraten bei Personen, die auf eine Intensivstation aufgenommen werden mussten oder verstorben sind, bei 73\% lag [19]. Bereits nach den ersten Publikationen wurde deutlich, 
Tab. 5 Klinische Symptome bei einer Infektion mit A(H1N1)v 2009 [19].

\begin{tabular}{|l|l|}
\hline Symptom & $\%$ \\
\hline Fieber & $96 \%$ \\
\hline Husten & $95 \%$ \\
\hline Kopfschmerzen & $61 \%$ \\
\hline allgemeines Krankheitsgefühl & $61 \%$ \\
\hline Pharyngitis & $60 \%$ \\
\hline Rhinitis & $59 \%$ \\
\hline Myalgie & $59 \%$ \\
\hline Diarrhö & $28 \%$ \\
\hline Dyspnoe & $26 \%$ \\
\hline Erbrechen & $13 \%$ \\
\hline
\end{tabular}

dass bei ca. 26-38\% der Erkrankten Anhalt für eine bakterielle pulmonale Superinfektion bestand, wobei Streptococcus pneumoniae der bei weitem dominierende bakterielle Erreger war $[17,42,44]$. Das führende klinische Syndrom, das zur Hospitalisierung auf Intensivstationen geführt hat, war eine virale Pneumonitis mit schwerer Hypoxämie, ARDS und Multiorganversagen $[13,41]$. Dieses Syndrom entwickelte sich in der Regel 4-5 Tage nach dem Beginn der klinischen Symptomatik der Grippe. Radiologisch imponierten im Röntgenbild des Thorax unregelmäßige weiche Infiltrate von mäßiger Ausdehnung. Das Ausmaß der Lungenerkrankung wurde häufig erst im CT-Thorax deutlich, das ausgedehnte Milchglas-Infiltrate und alveoläre Infiltrate zeigte $[13,41]$.

Vereinzelt wurde auch über neurologische Komplikationen (Konfusion, Koma, Enzephalitis, Paresen), Myokarditiden und Myositiden, z.T. mit letalem Ausgang, berichtet [13].

\section{Laborbefunde}

Im Blutbild wurden Lymphopenien beobachtet. Die Entzündungsparameter LDH und CRP waren deutlich erhöht $[19,20]$. Pathologische Leberwerte, d.h. erhöhte Serum-Transaminasen, fanden sich nach Daten aus den USA bei wegen Influenza hospitalisierten Patienten bei $45 \%[19,20]$. Aus der eigenen Erfahrung und nach den bisher publizierten Daten kann darüber hinaus aufgeführt werden, dass eine zum Teil massive Erhöhung der CK-Werte (Kreatininkinase) ebenfalls häufig (bis zu 30\% der hospitalisierten Influenza-Patienten) beobachtet worden sind $[13,41]$.

\section{Risiko-Population für schwere Verläufe bei einer $A(H 1 N 1) v$ 2009-Infektion}

Wie oben bereits ausführlich ausgeführt, waren von hospitalpflichtigen oder tödlich verlaufenden Influenza-Infektionen insbesondere Menschen unterhalb des 65. Lebensjahres betroffen. Die am meisten betroffene Altersgruppe war diejenige zwischen dem 18. und 49. Lebensjahr [19,22,23]. Aus den USA ist darüber hinaus von einer stark erhöhten Rate pädiatrischer Todesfälle ( $<5$ Jahre) berichtet worden. Während die Anzahl pädiatrischer Todesfälle in der Influenza-Saison 2006/
2007 78, in der Saison 2007/2008 88 und in der Saison 2008/2009 130 pädiatrische Todesfälle gezeigt hat, fand sich in der Influenza-Saison 2009/ 2010 eine Anzahl von 221 an Influenza verstorbenen Kindern [23].

Schwere Verläufe und Todesfälle sind vor allem bei Patienten mit Grunderkrankungen berichtet worden, lediglich 25-50\% aller dieser Patienten wiesen keine Grunderkrankung auf $[13,18,22$, $23,25,41]$. Hervorzuheben sind hier insbesondere die Folgenden:

Asthma bronchiale, chronisch-obstruktive Atemwegserkrankung, Diabetes mellitus, iatrogene Immunsuppression, chronische kardio-vaskuläre Erkrankungen, chronische renale Erkrankungen, chronische neurologische Erkrankungen und Übergewicht (BMI > 30).

Bisher nicht gut erklärt ist, warum von den schweren Verläufen einer Infektion mit A(H1N1) v 2009 besonders auch Schwangere betroffen waren. In den USA und in Deutschland sind die Hospitalisierungsraten bei Schwangeren 4-6 6 höher gewesen als bei nicht Schwangeren [18,46-50]. Betroffen waren dabei insbesondere Schwangere im 2. und 3. Trimenon sowie auch Wöchnerinnen. Eventuell trägt die Verschiebung der Immunantwort bei Schwangeren von einer zellvermittelten hin zu einer humoralen Immunität und der damit verminderten Aktivität zytotoxischer T-Lymphozyten etwas zu dem erhöhten Risiko gegenüber Virusinfektionen bei [51].

Patienten, die auf einer Intensivstation behandelt werden mussten, zeigten häufig neben dem Bild eines akuten respiratorischen Versagens Krankheitszeichen, die für eine Multiorganbeteiligung der Infektion oder für eine, durch die Virusinfektion induzierte, überschießende Abwehrreaktion (cytokine storm) sprachen [52-56]. Auch wenn letztlich nur wenige Patienten intensivmedizinisch behandelt werden mussten, kamen durch den raschen Anstieg der Fallzahlen die Intensivstationen auf der Süd- und Nord-Hemisphäre ebenso schnell an ihre Kapazitätsgrenzen [5256], wie dies auch in Deutschland der Fall war (persönliche Mitteilung Prof. Dr. T. Welte, MH Hannover).

\section{Therapie}

nAH1/N1 ist empfindlich gegenüber den Neuraminidase-Inhibitoren Oseltamivir (Tamiflu) und Zanamivir (Relenza) und resistent gegenüber Amantadin und Rimantadin. Die wenigen weltweit beobachteten Oseltamivir-resistenten Stämme waren Zanamivir-empfindlich [30]. Wegen seiner systemischen Verfügbarkeit und Wirksamkeit ist das orale Präparat Oseltamivir gegenüber dem mehr topisch wirksamen, inhalativ anzuwendenden Zanamivir weltweit bevorzugt eingesetzt worden. Je früher die Neuraminidase-Inhibitoren eingesetzt werden, desto sicherer ist ihre Wirksamkeit. Jedoch scheint bei schweren Verlaufsformen auch ein späterer Therapiebeginn (> 48 
Stunden nach Beginn der Symptomatik) einen positiven Effekt hinsichtlich der Krankheitsschwere und dem Überleben zu haben [30,57]. Bei milden bis mäßig schweren Erkrankungen wurde die Standard-Dosis von Oseltamivir mit $2 \times 150 \mathrm{mg} /$ Tag eingesetzt, bei schweren Verlaufsformen sind jedoch auch erfolgreich hohe Dosen $(2 \times 150 \mathrm{mg}-$ $2 \times 450 \mathrm{mg} / \mathrm{Tag}$ ) angewendet worden $[13,30]$. Bei schwerkranken Intensivpatienten fand sich allerdings, vermutlich durch eine verminderte Resorption nach oraler Applikation, teilweise eine unzureichende klinische Wirksamkeit der Oseltamivir-Therapie. In einigen solcher Fälle ist erfolgreich parenterales Zanamivir zum Einsatz gekommen (Off-Label-Use der nicht zugelassenen Sub$\operatorname{stanz)}[31]$.

\section{Grippeschutzimpfung}

Für die jährliche Herstellung von saisonalen Grippeschutzimpfstoffen werden als Saatviren Antigen-Drift-Varianten verwendet, die nach Meinung einer von der WHO koordinierten Expertengruppe in der kommenden Saison ein epidemiologisches Problem darstellen können. Grundsätzlich handelt es sich bei der saisonalen Grippeschutzimpfung um eine Auffrischungsimpfung, da eine Grundimmunität durch vorherige Impfungen oder abgelaufene Infektionen mit saisonalen Influenza-Stämmen vorhanden ist [58].

Das Risiko für schwere Verläufe oder Tod liegt bei der saisonalen Influenza insbesondere bei Personen, die 60 Jahre oder älter sind, und bei Personen mit schweren Grunderkrankungen. Für diese beiden Patientengruppen besteht daher eine vorrangige Impfindikation [59].

Die am weitesten verbreiteten saisonalen Influenza-Impfstoffe sind trivalente Spaltvirus-Vakzine. Diese werden überwiegend im Brutei-Herstellungsverfahren produziert. Ein kleinerer Teil der trivalenten Spalt-Vakzine wird in Hundenierenzellen oder in Affennierenzellen hergestellt. Neben den nicht adjuvantierten trivalenten SpaltVakzinen gibt es eine adjuvantierte trivalente Spalt-Vakzine der Firma Novartis (Fluad), bei der das Adjuvanz MF59.1 zum Einsatz kommt. Bisher nur in den USA bei Kindern eingesetzt wird eine saisonale Ganzvirus-Vakzine, bei der es sich um ein Kälte-attenuiertes rekombinant hergestelltes, vermehrungsfähiges Influenza-Virus handelt $[58,60]$.

Über die Schutzwirkung der saisonalen Influenza-Vakzine ist ausreichend Information vorhanden. Im Jahre 2007 wurde in einer Cochrane-Analyse festgestellt, dass die Untersuchung von 25 Studien mit insgesamt 59.566 Personen eine Effektivität der inaktivierten trivalenten Spalt-Vakzine von $70 \%$ ergeben hat, wobei der Vertrauensbereich zwischen 56 und 80\% lag [61]. Allerdings ist seit längerem bekannt, dass insbesondere bei Personen oberhalb des 65. Lebensjahres die Effektivität der saisonalen Influenza-Vakzine lediglich bei $52-60 \%$ anzusiedeln ist und einen großen
Vertrauensbereich aufweist (29-67\%) [59]. Zurzeit werden von den großen Impfstoff-Herstellern verschiedene Strategien verfolgt, die Effektivität der saisonalen Influenza-Vakzine insbesondere bei älteren Personen zu steigern. Eine aktuelle Strategie basiert auf der intradermalen Gabe des Impfstoffes unter Ausnutzung der intradermal hohen Dichte Antigen-präsentierender dentritischer Zellen $[58,62]$. Die zweite Strategie beinhaltet die Adjuvantierung der trivalenten Spaltvirus-Vakzine [58]. Dieser Weg ist von der Firma Novartis bereits vor einigen Jahren begonnen worden. Mit dem durch MF59.1 adjuvantierten saisonalen Impfstoff (Fluad) waren vor der Pandemie bisher ca. 40 Millionen weltweit geimpft worden. Effektivitätsdaten liegen hierzu jedoch nicht vor. Die Firma GSK führt seit 2008/2009 eine große Effektivitätsstudie mit mehr als 40000 Personen im Alter von über 65 Jahren mit einer trivalenten Spaltvirus-Vakzine durch, die mit dem Adjuvanz AS 03 kombiniert ist $[63,64]$.

Adjuvanzien dienen, vereinfacht ausgedrückt, dazu, am Ort der Injektion des Impfstoffes eine intensivierte lokale Entzündung zu induzieren. Hierdurch werden mehr immunkompetente Zellen am Ort der Antigengabe akkumuliert, und es kommt zu einer intensivierten immunologischen Verarbeitung der Antigene [58].

Bei der Entwicklung eines Impfstoffes gegen die Neue Influenza A(H1N1)v 2009 war die Ausgangssituation im Vergleich zur Entwicklung saisonaler Grippeschutzimpfstoffe vollkommen unterschiedlich. Es handelte sich um ein AntigenShift-Virus, bei dem davon ausgegangen werden musste, dass bei Personen, die jünger als 60 Jahre alt sind, keine Grundimmunität vorhanden ist. Ziel der Impfung war hier also nicht eine Auffrischung vorhandener Grundimmunität, sondern die Induktion einer Grundimmunität [58]. Diese Situation war vergleichbar mit der Entwicklung eines Impfstoffes gegen ein potenziell humanpathogenes aviäres Influenza-Virus wie zum Beispiel A/H5N1.

Bei Beginn der Krankheitswelle durch die Neue Influenza A(H1N1)v 2009 im April 2009 lagen bereits Erfahrungen aus der zweijährigen Entwicklung von Musterimpfstoffen gegenüber A/H5N1 vor [58]. Da man bei der Entwicklung eines Impfstoffes gegen ein hoch pathogenes aviäres Influenza-Virus davon ausgehen musste, dass das Brutei-Herstellungsverfahren sich durch die aviäre Pathogenität des Saatvirus gegenüber den Hühnerembryonen als schwierig erweisen könnte und somit nur eine geringe Antigen-Produktionskapazität erwartet werden konnte, musste nach einem Ausweg aus dieser Situation gesucht werden. Aus der Entwicklung von Musterimpfstoffen gegenüber $\mathrm{A} / \mathrm{H} 5 \mathrm{~N} 1$ wusste man, dass die für eine Grundimmunisierung notwendige Antigenmenge in der Größenordnung von 15-30 $\mu$ g Antigen lag [58]. Insbesondere im weltweiten Maßstab war jedoch auch unter der hypothetisch angenomme-

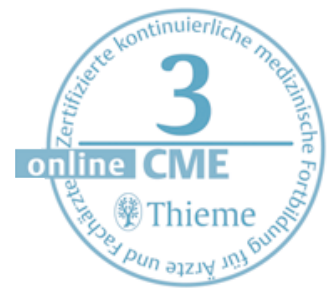


nen günstigen Voraussetzung, dass sich das Saatvirus nicht als Hühnerembryonen-pathogen erweisen würde, keine ausreichend hohe Herstellerkapazität für die Produktion derart hoher Antigenmengen vorhanden.

Die Entwicklung eines Vogelgrippe-Impfstoffes konzentrierte sich daher auf die Entwicklung von entweder adjuvantierten Impfstoffen zur Einsparung der notwendigen Antigenmenge oder die Herstellung von Ganzvirus-Impfstoffen [58]. Bereits frühzeitig in dieser Entwicklung zeigte sich, dass ein häufig eingesetztes Adjuvanz, nämlich Aluminium-Hydroxid, bei nicht vorhandener Grundimmunität keine wirksame Adjuvanzstrategie darstellte. Hingegen konnte gezeigt werden, dass sowohl das von der Firma Novartis entwickelte Adjuvanz MF59.1 als auch das von der Firma GSK entwickelte Adjuvanz AS 03 wirksam waren [58]. Aus der Musterzulassung pandemischer Impfstoffe gegenüber A/H5N1 war bekannt, dass die Serumprotektionsrate, d. h. der Anteil der Personen mit einem Hämagglutinin-Inhibitionstiter von > $1: 40$ nach zweimaliger Impfung am Tag 21 für 7,5 $\mu$ g Antigen plus MF59.1 bei $86 \%$, für 3,75 $\mu \mathrm{g}$ Antigen plus AS 03 bei $94,3 \%$ und für $7,5 \mu \mathrm{g}$ Ganzvirus-Antigen bei 65\% lag [58]. Auf der Basis dieser Musterzulassung von Pandemie-Impfstoffen gegenüber dem Vogelgrippe-Virus sind dann die Pandemie-Impfstoffe gegenüber $\mathrm{A}(\mathrm{H} 1 \mathrm{~N} 1) \mathrm{v}$ 2009 entwickelt worden.

Bei den Adjuvanzsystemen MF59 und AS 03 handelt es sich um Öl-in-Wasser-Emulsionen aus Squalen (einem Zwischenprodukt der Cholesterin-Biosynthese, gewonnen z.B. aus Haifischleber) als Ölphase und einer Wasserphase (MF 59 Zitratpuffer; AS 03: PBS). AS 03 enthält zusätzlich Alpha-Tocopherol (11,6 $\mu \mathrm{g}$ Vitamin E) [58].

Da Squalen ein Zwischenprodukt der endogenen humanen Cholesterin-Biosynthese ist, ist Squalen bei entsprechend sensiblen Verfahren im Blut des Menschen nachweisbar. Die tägliche Aufnahme durch Nahrungsmittel, insbesondere durch Fische und Olivenöl, liegt bei ca. $10 \mu \mathrm{g}$. Im Gegensatz zu in den Medien vielfältig geäußerten Befürchtungen fanden sich bei mit Squalen-haltigen Impfstoffen geimpften US-amerikanischen Soldaten, die am ersten Golfkrieg teilgenommen hatten, keine vermehrten Erkrankungen oder schwerwiegenden unerwünschten Wirkungen [65]. Darüber hinaus lagen vor der Infektion gegen das neue Influenza-Virus mit dem Adjuvanzsystem MF59.1 der Firma Novartis Erfahrungen aus 40

Tab. 6 Surogatparameter der Impfwirksamkeit für Pandemrix ${ }^{\circledR}$ bei Erwachsenen [65].

\begin{tabular}{|c|c|c|}
\hline & Ziel & $\begin{array}{l}\text { Altersgruppe } \\
18-60 \text { Jahre }\end{array}$ \\
\hline Serumkonversionsfaktor (mittlerer Anstieg HAI-AK) & $\geq 2,5$ & $\geq 42$ \\
\hline $\begin{array}{l}\text { Serokonversionsrate }(\%) \\
\text { (\% HAI-Titer }<1: 40 \text { vor und > 1:40 nach Impfung) }\end{array}$ & $\geq 40$ & 95 \\
\hline $\begin{array}{l}\text { Seroprotektionsrate }(\%) \\
\text { (\% mit HAl-Titer > 1: } 40 \text { nach Impfung) }\end{array}$ & $\geq 70$ & $>98$ \\
\hline
\end{tabular}

Millionen Impfungen mit saisonalen Grippevirus-Antigenen vor $[66,67]$ und aus den klinischen Studien im Rahmen der Musterzulassung für einen Vogelgrippe-Impfstoff mit dem Adjuvanzsystem AS 03 der Firma GSK Erkenntnisse über mehr als 40000 im Rahmen der Entwicklung dieses Impfstoffes untersuchten Probanden vor [64].

Das Paul-Ehrlich-Institut in Deutschland und die europäischen Arzneimittel-Zulassungsbehörden sehen eine Wirksamkeit einer Influenza-Vakzine dann als gegeben an, wenn der Sero-Konversionsfaktor, also der mittlere Anstieg der HAI-Antikörpertiter, > 2,5 ist, die Serum-Konversionsrate, also der Anteil der Personen mit einem HAI-Titer von $<40$ vor und $>40$ nach der Impfung oder 4-fachem Titeranstieg, wenn der HAI-Titer vor der Impfung > 1:40 war, bei 40\% der Impflinge erreicht wird und die Serum-Protektionsrate, d.h. der Anteil der Personen mit einem HAI-Titer von $>40$ nach der Impfung über 70\% liegt [58].

Nach Auswertungen der ersten Resultate der Impfung mit dem Impfstoff Pandemrix ${ }^{\circledR}$ der Firma GSK $(3,75 \mu$ g Antigen A(H1N1)V 2009 plus AS 03) zeigte sich, dass in der Altersgruppe der 18bis 60-Jährigen die folgenden Wirksamkeitswerte erreicht worden sind: Serum-Konversionsfaktor 42, Serumkonversionsrate 95\%, Serumprotektionsrate $98 \%$.

Im Verlauf zeigte sich auch für Kinder, d.h. Personen unterhalb des 18. Lebensjahres, dass ähnliche Wirksamkeitskriterien bereits mit einer einzigen Impfung erreichbar waren [65].

Ähnlich hohe Wirksamkeitsnachweise hat der Impfstoff Focetria der Firma Novartis (7,5 $\mu \mathrm{g}$ Antigen plus MF59.1) ergeben [65]. Etwas schlechter waren die Wirksamkeitsnachweise für den Ganzvirusimpfstoff Celvapan der Firma Baxter [65]. In ähnlicher Größenordnung wie die adjuvantierten Impfstoffe waren auch die nicht adjuvantierten Impfstoffe wirksam, die $15 \mu \mathrm{g}$ A(H1N1)v 2009Antigen enthielten. Diese Impfstoffe sind insbesondere in den USA, Canada und Australien zum Einsatz gekommen [68].

Aus globaler Sicht muss allerdings klar festgestellt werden, dass die Strategie, einen Impfschutz mit möglichst wenig Antigen zu induzieren, nicht nur eine günstige Strategie für den Fall einer möglichen aviären Toxizität des Saatvirus war, sondern auch die Möglichkeit bot, weltweit bedeutend mehr Impfstoff zur Verfügung zu stellen als beim Einsatz hoher Antigenmengen. Daher bieten die adjuvantierten Impfstoffe auch die Möglichkeit, im weltweiten Maßstab bedeutend mehr (2 $-4 \times$ mehr) Menschen zu impfen als beim Einsatz höherer Antigenmengen.

Neben der Kritik an den Adjuvanzsystemen galt ein Teil der öffentlichen Kritik an dem in Deutschland eingesetzten Impfstoff Pandemrix ${ }^{\circledR}$ die Tatsache, dass der Impfstoff in Mehrdosis-Behältern zur Verfügung gestellt worden ist. Diese Mehrdosis-Behälter enthielten das antibakteriell wirksame Quecksilbersalz Thiomersal. Die in einer 
Impfdosis enthaltene Tiomersalmenge betrug 5 $\mu \mathrm{g}$, die resorbierbare Quecksilbermenge 2,5 $\mu$ g. Hierbei ist zu bedenken, dass die erlaubte wöchentliche Quecksilberaufnahme innerhalb der Europäischen Gemeinschaft durch die Nahrung als oberen Grenzwert $0,7 \mu \mathrm{g} / \mathrm{kg}$ Körpergewicht pro Woche erlaubt, dies entspricht bei einem 70 $\mathrm{kg}$ schweren Menschen ca. $50 \mu \mathrm{g}$ pro Woche, also das 20-Fache dessen, was bei der Impfung verabreicht worden ist [69].

\section{Unerwünschte Wirkungen des Impfstoffes Pandemrix ${ }^{\circledR}$}

Dem Paul-Ehrlich-Institut sind bis zum 19.1.2010 nach der Verimpfung von ca. 6-7 Millionen Dosen unerwünschte Arzneimittelwirkungen bei 1.377 Personen gemeldet worden [65]. Insgesamt wurden bei diesen Personen 3.518 Ereignisse gemeldet (Mehrfachnennungen möglich). Überwiegend handelt es sich hierbei um eine deutlich verstärkte Lokalreaktion, kurzfristige subfebrile Temperaturen oder kurzfristiges Fieber, Kopfschmerzen, Übelkeit und allgemeine Mattigkeit. Die Rate der Meldungen schwerer unerwünschter Arzneimittelwirkungen unterscheidet sich bis zum oben genannten Datum nicht von der Meldungsrate, wie sie zwischen den Jahren 2000 und 2008 über die saisonalen Impfstoffe berichtet worden ist. Auch im europäischen Maßstab kann festgestellt werden, dass möglicherweise durch den Impfstoff induzierte schwere, unerwünschte Arzneimittelwirkungen oder Todesfälle das statistisch erwartbare Risiko für das Eintreten solcher Erkrankungen oder den Tod nicht überschreiten, d.h. bisher gibt es für Impfstoff-bezogene, schwere unerwünschte Wirkungen oder Impfstoff-bezogene Todesfälle keine statistisch nachweisbare Häufung [70].

\section{Rückblick auf die Saison 2009/2010}

Die Entwicklung der A(H1N1)v 2009-Pandemie war, wie oben beschrieben, sehr rasch. Das neue Antigen-Shift-Virus traf auf eine zum großen Teil immunologisch naive Bevölkerung (Personen < 64 Lebensjahre). Verglichen mit vorausgehenden Pandemien war jedoch die Pathogenität des neuen Virus weniger stark ausgeprägt. Somit war trotz hoher Übertragungsfähigkeit und Ansteckungsfähigkeit des Virus häufig ein milder Krankheitsverlauf zu beobachten. Bei einem kleinen Teil der Erkrankten hat sich jedoch ein schwerwiegendes Krankheitsbild entwickelt, wobei insbesondere vermutlich primäre virale Pneumonien zu einer Vielzahl von auf Intensivstationen zu versorgenden Patienten führte. Zusätzlich zeigten schwere Verläufe häufig die Entwicklung einer sekundären bakteriellen Pneumonie. Betroffen waren weltweit überwiegend jüngere Menschen und vor allem Kinder, Jugendliche und junge Erwachsene.

Das neue A(H1N1)v 2009-Virus hat sich als relativ stabil erwiesen. Eine wesentliche Resistenzent- wicklung ist bisher nicht eingetreten. Ebenso ist bisher keine Virulenzsteigerung beobachtet worden. Allerdings war das Virus in der Lage, die saisonalen Influenza-Viren nahezu komplett weltweit zu verdrängen. Die Pandemie 2009/2010 traf die Welt nicht unvorbereitet. Bedingt durch die SARS-Epidemie und die Entwicklung hoch pathogener aviärer Influenza-Viren (H5N1) war die Entwicklung von Managementplänen des öffentlichen Gesundheitswesens, die Entwicklung von raschen diagnostischen Instrumenten (PCR) und die Entwicklung von Impfstoffen bereits vor Beginn der Pandemie gut vorangeschritten. Ein nach Analyse aller bisher vorliegenden Daten hoch wirksamer und gut verträglicher Impfstoff stand rasch, wenn auch etwas verspätet (Höhepunkt der Impfstoffproduktion und Auslieferung bzw. Verfügbarkeit zum Verimpfen im Höhepunkt der 2. Krankheitswelle im November 2009) zur Verfügung.

Insofern ist der Erkenntnisgewinn, den die Öffentlichkeit und die Wissenschaft durch die Epidemie 2009/2010 gehabt hat, nicht zu unterschätzen. Man kann davon ausgehen, dass die Welt nach der Erfahrung des vergangenen Jahres besser auch für eine deutlich schwerer verlaufende pandemische Situation gerüstet ist.

Kritisch anmerken muss man, dass es bei der Kommunikation zwischen Wissenschaft, öffentlichem Gesundheitswesen und staatlichen Instanzen eine Reihe von Problemen gegeben hat. Dies fängt mit der Namensgebung des Virus in den Medien (Schweinegrippe) an. Diese Namensgebung induzierte bei vielen Menschen die Vorstellung, dass es sich bei A(H1N1)v 2009 um ein tierpathogenes und nicht humanpathogenes Virus gehandelt hat. Im weiteren Verlauf wurde die Deklaration der Pandemiestufe 6 durch die WHO dahingehend missverstanden, dass hohe Erwartungen an exorbitante Raten schwerer Erkrankter und eine sehr hohe Letalität verknüpft wurden, ohne dass die Grundlage der Definition, nämlich die weltweite Verbreitung eines neuen Virustyps, hierbei gebührend gewürdigt wurde. Selbstkritisch muss darüber hinausgehend festgestellt werden, dass sich insbesondere zu Beginn der Pandemie und in der Vorbereitung der Impfkampagne viele Kolleginnen und Kollegen in den Medien geäußert haben, ohne über eine erkennbare Expertise hinsichtlich der Influenza zu verfügen. Dies hat insbesondere hinsichtlich des zur Verfügung stehenden Impfstoffes zu einer tiefen Verunsicherung der Bevölkerung und daraus resultierender mangelnder Akzeptanz der Impfung geführt. Schließlich war auch das Agieren des Staates, insbesondere hinsichtlich der Beschaffung der Impfstoffe, unglücklich. Die Bevorratung eines anders gearteten Impfstoffes für bestimmte Teile staatlicher Organe als für die gesamte Bevölkerung hat in der Öffentlichkeit zu großen Irritationen geführt und gleichzeitig den Eindruck erweckt, bei dem für die Öffentlichkeit zur Verfügung stehen-

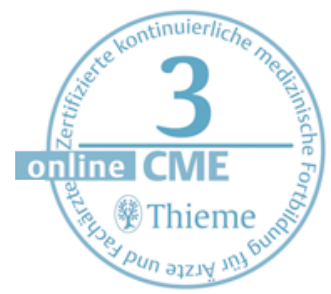


den pandemischen Impfstoff handelte es sich um ein Präparat 2. Klasse. Angesichts der unzureichenden Durchimpfungsrate der Bevölkerung ist dieses besonders zu bedauern. Wir gehen zurzeit davon aus, dass in Deutschland etwas weniger als $10 \%$ der Bevölkerung gegen A(H1N1)v 2009 geimpft sind [65]. In Schweden hat die Durchimpfungsrate der Bevölkerung hingegen mehr als 50\% erreicht. Somit besteht hier in einem deutlich höheren Ausmaß eine Grundimmunität gegenüber dem neuen Influenza-Virus [71].

\section{Ausblick auf die Saison 2010/2011}

Nach Abklingen der pandemischen Welle in den USA und Europa ist es auf der Südhemisphäre nicht zur Entwicklung einer neuen Frühjahrs-Epidemie gekommen. Somit wird zurzeit auch für die Nordhemisphäre nicht mit einer Sommerwelle, verursacht durch $\mathrm{A}(\mathrm{H} 1 \mathrm{~N} 1) \mathrm{v} 2009$, gerechnet. Es wird interessant zu beobachten, wie sich die Situation im Winterhalbjahr der Südhemisphäre entwickelt. Hieraus können vermutlich Rückschlüsse auf die Entwicklung der Influenza-Epidemie im Winter 2010/2011 auf der Nordhemisphäre gezogen werden. Da sich nAH1/N1 jedoch in der Saison 2009/2010 weltweit verbreitet und eine große Zahl von Menschen sich infiziert hat, ist das pandemische Potenzial des Virus vermutlich erschöpft. Nach Modellberechnungen des RKI ist davon auszugehen, dass zurzeit durch abgelaufene Infektionen, Impfungen und Kreuzimmunität (bei den > 60-Jährigen) 26-44\% der Bevölkerung schützende Antikörperspiegel gegen $A(H 1 N 1) v 2009$ aufweisen [22]. Zu rechnen ist allerdings damit, dass sich dieses Virus als saisonales Influenza-Virus etabliert. Hinsichtlich der Zusammensetzung eines Impfstoffes für die Saison 2010/2011 wäre es daher wünschenswert, neben A(H1N1)v 2009 eine Impfstoffkomponente zu A/H3N2 und Influenza B hinzuzunehmen. Eine solche Vakzine wird voraussichtlich gemäß Empfehlungen der WHO als trivalente, nicht-adjuvantierte Spaltvakzine angeboten werden. Die STIKO berät derzeit nach den Erfahrungen des vergangenen Jahres über etwaige Erweiterung der Standard-Indikationsgruppen; hier könnten Schwangere oder Personen mit Grunderkrankungen einbezogen werden.

\section{Interessenkonflikte}

$\nabla$

Die Autoren geben an, dass kein Interessenkonflikt besteht.

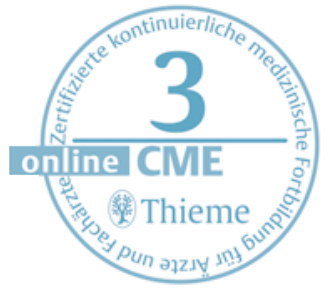

Literatur

1 Fedson DS. Was bacterial pneumonia the predominant cause of death in the 1918-1919 influenza pandemic? J Infect Dis 2009; 199: 1408-1409

2 Starko KM. Salicylates and pandemic influenza mortality, 1918-1919 pharmacology, pathology, and historic evi-
3 Shinde V, Bridges CB, Uyeki TM et al. Triple-reassortant swine influenza $A(\mathrm{H} 1)$ in humans in the United States, 2005 -2009. N Engl J Med 2009; 360: 2616-2625

4 Bastien N, Antonishyn NA, Brandt Ket al. Human infection with a triple-reassortant swine influenza $A(H 1 N 1)$ virus containing the hemagglutinin and neuraminidase genes of seasonal influenza virus. J Infect Dis 2010; 201: 1178 1182

5 Garten RJ, Davis CT, Russell CA et al. Antigenic and genetic characteristics of swine-origin 2009 A(H1N1) influenza viruses circulating in humans. Science 2009; 325: $197-$ 201

6 Lessler J, Reich NG, Cummings DA et al. Outbreak of 2009 pandemic influenza A (H1N1) at a New York City school. N Engl J Med 2009; 361: 2628 - 2636

7 Yang Y, Sugimoto JD, Halloran ME et al. The transmissibility and control of pandemic influenza $A(H 1 N 1)$ virus. Science 2009; 326: 729-733

8 Fraser C, Donnelly CA, Cauchemez S et al. Pandemic potential of a strain of influenza A (H1N1): early findings. Science 2009; 324: 1557-1561

9 White LF, Wallinga J, Finelli $L$ et al. Estimation of the reproductive number and the serial interval in early phase of the 2009 influenza A/H1N1 pandemic in the USA. Influenza Other Respi Viruses 2009; 3: 267 - 276

10 Libster R, Bugna J, Coviello $S$ et al. Pediatric hospitalizations associated with 2009 pandemic influenza A (H1N1) in Argentina. N Engl J Med 2010; 362: 45 - 55

11 Hancock $K$, Veguilla $V$, Lu $X$ et al. Cross-reactive antibody responses to the 2009 pandemic H1N1 influenza virus. N Engl J Med 2009; 361: 1945 - 1952

12 Greenbaum JA, Kotturi MF, Kim Y et al. Pre-existing immunity against swine-origin H1N1 influenza viruses in the general human population. Proc Natl Acad Sci U S A 2009; 106: 20365 - 20370

13 Bautista E, Chotpitayasunondh T, Gao Z et al. Clinical Aspects of Pandemic 2009 Influenza A (H1N1) Virus Infection. N Engl J Med 2010; 362: 1708 - 1719

14 Itoh $Y$, Shinya $K$, Kiso $M$ et al. In vitro and in vivo characterization of new swine-origin $\mathrm{H} 1 \mathrm{~N} 1$ influenza viruses. Nature 2009; 460: 1021 - 1025

15 Munster VJ, de Wit G, van den Brand JM et al. Pathogenesis and transmission of swine-origin $2009 \mathrm{~A}(\mathrm{H} 1 \mathrm{N1} 1)$ influenza virus in ferrets. Science 2009; 325: 481 - 483

16 Chowell G, Bertozzi SM, Colchero MA et al. Severe respiratory disease concurrent with the circulation of H1N1 influenza. N Engl J Med 2009; 361: 674-679

17 Mauad T, Hajjar LA, Callegari GD et al. Lung pathology in fatal novel human influenza A (H1N1) infection. Am J Respir Crit Care Med 2010; 181: 72 - 79

18 Robert-Koch-Institut. Influenza. http://www.rki.de/influenza; Stand: 2010

19 Jain S, Kamimoto L, Bramley AM et al. Hospitalized patients with 2009 H1N1 influenza in the United States, April-june 2009. N Engl J Med 2009; 361: 1935 - 1944

20 Louie JK, Acosta M, Winter $K$ et al. Factors associated with death or hospitalization due to pandemic 2009 influenza $\mathrm{A}(\mathrm{H} 1 \mathrm{N1})$ infection in California. JAMA 2009; 302: 1896 1902

21 Garske T, Legrand J, Donnelly CA et al. Assessing the severity of the novel influenza A/H1N1 pandemic. BM] 2009; 339: b2840

22 ECDC. ECDC pandemic flu. http://www.ecdc.europa.eu/ en/healthtopics/h1n1/pages/home.aspx; Stand: 2010

23 CDC. CDC flu view. http://www.cdc.gov/flu/weekly/; Stand: 2010

24 Haas W. Pandemieplanung. In: Haas W, Hrsg. Influenza. München: Urban\&Fischer; 2009: 209-230 dence. Clin Infect Dis 2009; 49: 1405-1410
25 WHO. Pandemic (H1N1) 2009 -update 94. http.//www. who.int/crs/2010_04_01/en/index.html; Stand: 2010

26 Miller E, Hoschler $K$, Hardelid $P$ et al. Incidence of 2009 pandemic influenza A H1N1 infection in England: a cross-sectional serological study. Lancet 2010; 375: $1100-1108$ 
27 Ross T, Zimmer S, Burke D et al. Seroprevalence Following the Second Wave of Pandemic 2009 H1N1 Influenza. PLoS Curr Influenza 2010; RRN1148

28 Neumann G, Noda T, Kawaoka Y. Emergence and pandemic potential of swine-origin H1N1 influenza virus. Nature 2009; 459: 931 - 939

29 Baz M, Abed Y, Papenburg / et al. Emergence of oseltamivir-resistant pandemic H1N1 virus during prophylaxis. N Engl J Med 2009; 361: 2296 - 2297

30 WHO. WHO guidelines for pharmacological management of pandemic (H1N1) 2009 influenza. http://www. who.int/csr/resources/publications/swineflu/ h1n1_use_antivirals; Stand: 2010

31 Gaur AH, Bagga B, Barman S et al. Intravenous zanamivir for oseltamivir-resistant 2009 H1N1 influenza. N Engl ] Med 2010; 362: 88 - 89

32 Schaberg T, Bauer T, Dalhoff $K$ et al. Management of a new influenza $A / H 1 N 1$ virus pandemic within the hospital. Statement of the German Society of Pneumology 2010 update. Pneumologie 2010; 64: 124-129

33 Blyth CC, Iredell JR, Dwyer DE. Rapid-test sensitivity for novel swine-origin influenza $A(\mathrm{H} 1 \mathrm{~N} 1)$ virus in humans. N Engl ] Med 2009; 361: 2493

34 Cauchemez S, Donnelly CA, Reed C et al. Household transmission of 2009 pandemic influenza A (H1N1) virus in the United States. N Engl J Med 2009; 361: 2619-2627

35 De Serres G, Rouleau I, Hamelin ME et al. Contagious period for pandemic (H1N1) 2009. Emerg Infect Dis 2010; 16: $783-788$

36 To KK, Chan KH, Li IW et al. Viral load in patients infected with pandemic H1N1 2009 influenza A virus. J Med Virol 2010; 82: $1-7$

37 To KK, Hung IF, Li IW et al. Delayed clearance of viral load and marked cytokine activation in severe cases of pandemic H1N1 2009 influenza virus infection. Clin Infect Dis 2010; 50: $850-859$

38 Cao B, Li XW, Mao Y et al. Clinical features of the initial cases of 2009 pandemic influenza A (H1N1) virus infection in China. N Engl ] Med 2009; 361: 2507 - 2517

39 Perez CM, Ferres M, Labarca JA. Pandemic (H1N1) 2009 reinfection, Chile. Emerg Infect Dis 2010; 16: 156-157

40 Schaberg T. Klinische Präsentation der Influenza beim Erwachsenen. In: Haas W, Hrsg. Influenza. München: Urban \& Fischer; 2009: 155- 166

41 Miller RR III, Markewitz BA, Rolfs RT et al. Clinical findings and demographic factors associated with ICU admission in Utah due to novel 2009 influenza $A(H 1 N 1)$ infection. Chest 2010; 137: $752-758$

42 Gill JR, Sheng ZM, Ely SF et al. Pulmonary pathologic findings of fatal 2009 pandemic influenza A/H1N1 viral infections. Arch Pathol Lab Med 2010; 134: 235-243

43 Gomez-Gomez A, Magana-Aquino M, Garcia-Sepulveda C et al. Severe pneumonia associated with pandemic (H1N1) 2009 outbreak, San Luis Potosi, Mexico. Emerg Infect Dis 2010; 16: 27 - 34

44 Palacios G, Hornig M, Cisterna D et al. Streptococcus pneumoniae coinfection is correlated with the severity of H1N1 pandemic influenza. PLoS One 2009; 4: e8540

45 Perez-Padilla R, de la Rosa-Zambon D, Ponce de Leon S et al. Pneumonia and respiratory failure from swine-origin influenza A (H1N1) in Mexico. N Engl J Med 2009; 361: $680-689$

46 ANZIC Influenza Investigators and Australasian Maternity Outcomes Surveillance System. Critical illness due to 2009 A/H1N1 influenza in pregnant and postpartum women: population based cohort study. BM] 2010; 340: c1279

47 Louie JK, Acosta M, Jamieson DJ, Honein MA. Severe 2009 H1N1 influenza in pregnant and postpartum women in California. N Engl I Med 2010; 362: 27 - 35

48 Mangtani P, Mak TK, Pfeifer D. Pandemic H1N1 infection in pregnant women in the USA. Lancet 2009; 374: 429 430

49 Siston AM, Rasmussen SA, Honein MA et al. Pandemic 2009 influenza $A(\mathrm{H} 1 \mathrm{~N} 1)$ virus illness among pregnant women in the United States. JAMA 2010; 303: 1517 1525
50 Jamieson DJ, Honein MA, Rasmussen SA et al. H1N1 2009 influenza virus infection during pregnancy in the USA. Lancet 2009; 374: 451 - 458

51 Yamaguchi K, Hisano M, Isojima S. Relationship of Th1/ Th2 cell balance with the immune response to influenza vaccine during pregnancy. J Med Virol 2009; 81: 1923 1928

52 Davies A, Jones D, Bailey $M$ et al. Extracorporeal Membrane Oxygenation for 2009 Influenza A(H1N1) Acute Respiratory Distress Syndrome. JAMA 2009; 302: $1888-$ 1895

53 Kumar A, Zarychanski R, Pinto $R$ et al. Critically ill patients with 2009 influenza $A(H 1 N 1)$ infection in Canada. JAMA 2009; 302: 1872 - 1879

54 Lister P, Reynolds F, Parslow R et al. Swine-origin influenza virus $\mathrm{H} 1 \mathrm{~N} 1$, seasonal influenza virus, and critical illness in children. Lancet 2009; 374: 605-607

55 Webb SA, Pettila V, Seppelt l et al. Critical care services and 2009 H1N1 influenza in Australia and New Zealand. N Engl J Med 2009; 361: 1925-1934

56 Webb SA, Seppelt IM. Pandemic (H1N1) 2009 influenza („swine flu“) in Australian and New Zealand intensive care. Crit Care Resusc 2009; 11: 170-172

57 WHO. WHO: Clinical management of human infection with pandemic (H1N1) 2009. http://www.who.int/csr/ resources/publications/swineflu/clinical_management/ en/index.html; Stand: 2010

58 Pfleiderer M. Influenzaimpfstoffe. In: Haas W, Hrsg. Influenza. München: Urban \& Fischer; 2009: 111 - 137

59 Heininger J. Möglichkeiten und Strategien der Impfprävention. In: Haas W, Hrsg. Influenza. München: Urban \& Fischer; 2009: 139-153

60 De Villiers PJ, Steele $A D$, Hiemstra $L A$ et al. Efficacy and safety of a live attenuated influenza vaccine in adults 60 years of age and older. Vaccine 2009; 28: $228-234$

61 Jefferson TO, Rivetti D, Di PC et al. Vaccines for preventing influenza in healthy adults. Cochrane Database Syst Rev 2007; (2): CD001269

62 Arnou R, Icardi G, De DM et al. Intradermal influenza vaccine for older adults: a randomized controlled multicenter phase III study. Vaccine 2009; 27: 7304-7312

63 Leroux-Roels I, Roman F, Forgus $S$ et al. Priming with AS03 A-adjuvanted $\mathrm{H} 5 \mathrm{~N} 1$ influenza vaccine improves the kinetics, magnitude and durability of the immune response after a heterologous booster vaccination: an open nonrandomised extension of a double-blind randomised primary study. Vaccine 2010; 28: 849-857

64 Roman F, Vaman T, Gerlach B et al. Immunogenicity and safety in adults of one dose of influenza A H1N1v 2009 vaccine formulated with and without AS03A-adjuvant: preliminary report of an observer-blind, randomised trial. Vaccine 2010; 28: 1740 - 1745

65 Paul-Ehrlich-Institut. Pandemische (H1N1) 2009-Influenza. http://www.pei.de/DE/infos/fachkreise/impf-fach/ schweineinfluenza/schweineinfluenza-node.html; Stand: 2010

66 Clark TW, Pareek M, Hoschler K et al. Trial of 2009 influenza A (H1N1) monovalent MF59-adjuvanted vaccine. N Engl J Med 2009; 361: 2424 - 2435

67 Vesikari T, Groth N, Karvonen A et al. MF59-adjuvanted influenza vaccine (FLUAD) in children: safety and immunogenicity following a second year seasonal vaccination. Vaccine 2009; 27: 6291-6295

68 Greenberg ME, Lai MH, Hartel GF et al. Response to a monovalent 2009 influenza A (H1N1) vaccine. N Engl ] Med 2009; 361: 2405-2413

69 European Food Safety Agency. Quecksilber. http://www. efsa.europa.eu/de/press/news/contam040318.htm; Stand: 2010

70 European Medicines Agency. Update on pandemic medicines. www.emea.europa.eu; Stand: 2010

71 Swedish MAP. MAP Safety Report. http://www.lakemedelsverket.se/english/All-news/NYHETER-2009/Summary-of-ADR-reports-in-Sweden-with-Pandemrix-; Stand: 2010

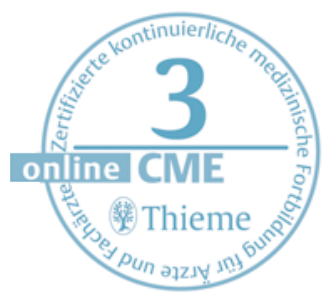




\section{CME-Fragen Die Influenza-Pandemie der Saison 2009/2010}

1 Welches Charakteristikum pandemischer Viren trifft auf A(H1N1)v 2009 nicht zu?

A antigener Shift

B hohe Transmissionsrate

C vermehrtes Auftreten von schweren Krankheitsverläufen in der Population der > 65-Jährigen

D Auftreten außerhalb der klassischen Grippesaison

E Auftreten in immunologisch naiven Populationen

2 Die Reproduktionszahl (Ro) der Neuen Influenza

$A(H 1 / N 1) v 2009$ lag bei

$\begin{array}{ll}\text { A } & 0,1-0,5 \\ \text { B } & 1,1-1,8 \\ \text { C } & 2,0-3,0 \\ \text { D } & 1-1,2 \\ \text { E } & >3,0\end{array}$

3 Welche Aussage ist nicht korrekt:

Auf dem Höhepunkt der Pandemie lag die Nachweisrate von $A(H 1 / N 1) v 2009$

A bei den 0- bis 1-Jährigen bei $27 \%$

B bei den 2- bis 4-Jährigen bei $34 \%$

C bei den 5 - bis 14 -Jährigen bei $62 \%$

D bei den 15 - bis 34 -Jährigen bei $44 \%$

E bei den $>60$-Jährigen bei $50 \%$

4 Welche Aussage ist richtig?

Der Höhepunkt der Pandemie in Deutschland lag

A zwischen der 29. und 35. Kalenderwoche 2009.

B zwischen der 35. und 43. Kalenderwoche 2009.

C zwischen der 43. und 52. Kalenderwoche 2009.

D in der 2. Kalenderwoche 2010.

E nach der 4. Kalenderwoche 2010.

5 Der Goldstandard zum Virusnachweis bei InfluenzaPandemien ist:

A Influenza A-Antigen-Schnelltest

B RT-PCR

C Viruskultur

D serologischer Nachweis von Antikörpern

E die indirekte Immunfluoreszenz
6

Welche Symptomatik oder welche klinischen Befunde waren untypisch für eine $A(H 1 / N 1) v$ 2009-Infektion?

A Erbrechen und Diarrhoe

B diffuse Schleimhautblutungen

C Fieber

D Pneumonien

E Hepatopathien

7 Welches ist keine typische Risikopopulation für einen schweren Krankheitsverlauf bei der A(H1/N1)v 2009Infektion?

A Asthmatiker

B Schwangere

C Säuglinge und Kleinkinder

D übergewichtige Patienten (BMI > 30)

E untergewichtige Patienten

8 Während der Pandemie war das Influenzavirus

A(H1/N1)v 2009 immer sensibel gegenüber

A Zanamivir

B Oseltamivir

C Amantadin

D Oseltamivir und Amantadin

E Zanamivir und Oseltamivir

9 Welcher Impfstoff hat keine klinische Schutzwirkung gegenüber $A(H 1 / N 1) v 2009$ ?

$\begin{array}{ll}\text { A } & \text { Pandemrix } \\ \text { B } & \text { Fluat } \\ \text { C } & \text { Celvapan } \\ \text { D } & \text { nicht-adjuvantierte A(H1/N1)v 2009-Vakzine } \\ \text { E } & \text { trivalente Spaltvakzine der Saison 2009/2010 }\end{array}$

10

Welche unerwünschten Arzneimittelwirkungen sind nach der Impfung mit Pandemrix ${ }^{\circledR}$ häufig beobachtet worden?

A Guillain-Barré-Syndrom

B Hämolysen

C Paresen

D Todesfälle

E verstärkte Lokalreaktionen

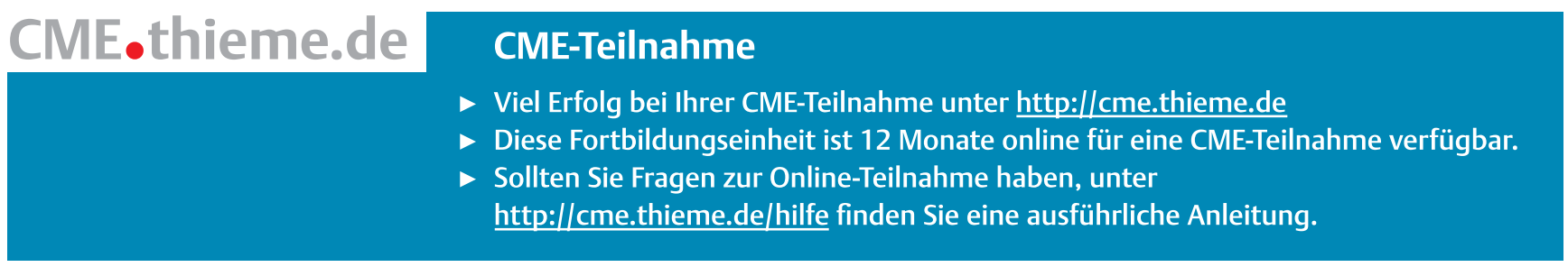

